\title{
A construção de indicadores de qualidade para a avaliação de recursos humanos nos serviços de enfermagem: pressupostos teóricos
}

\author{
The Development of Quality indicators to evaluate resources for nursing services: \\ Theoretical Presuppositions \\ La construcción de indicadores de calidad para la evaluación de los recursos humanos en los servicios \\ de enfermería: presuposicións teóricas
}

Paulina Kurcgant', Daisy Maria Rizatto Tronchin², Marta Maria Melleiro²

\section{RESUMO}

A construção de indicadores de qualidade visando a avaliação de serviços de enfermagem nas instituições hospitalares, vem caracterizandose como uma estratégia que possibilita a busca da eficiência e da eficácia das estruturas organizacionais, dos processos de trabalho e dos resultados da assistência prestada. Para explicitar os pressupostos teóricos envolvidos na construção de indicadores que possibilitem avaliar os recursos humanos na enfermagem foi realizada uma revisão bibliográfica, a qual subsidiou a construção de estratégias para a avaliação de recursos humanos em saúde. Acredita-se que a elaboração e a aplicabilidade de indicadores de qualidade guardam estreita relação com a motivação e satisfação dos profissionais, repercutindo na assistência prestada aos usuários dos serviços de saúde.

Descritores: Indicadores de qualidade em assistência à saúde; Garantia da qualidade dos cuidados de saúde; Recursos humanos em saúde.

\begin{abstract}
The development of quality indicators to evaluate nursing services in hospitals is an efficacious strategy to improve the structure of the organization, the working processes, and the delivery of care. To discuss theoretical presuppositions related to the development of quality indicators to evaluate human resources for nursing services. This study consisted of a literature review to identify strategies to evaluate human resources for health care services. The development and use of quality indicators are closely connected to professional motivation and satisfaction, which influence the delivery of care to users of health care services.
\end{abstract}

Keywords: Quality indicators; health care; Quality assurance; health care; Health manpower.

\section{RESUMEN}

La construcción de indicadores de calidad en vistas de la evaluación de los servicios de enfermería en las instituciones hospitalarias, viene caracterizándose como una estrategia que hace posible la búsqueda de la eficiencia y eficacia de las estructuras organizacionales, de los procesos de trabajo y de los resultados de la asistencia prestada. Para explicitar las premisas teóricas involucradas en la construcción de indicadores que hagan posible evaluar los recursos humanos en la enfermería se realizó una revisión bibliográfica, la cual subsidió la construcción de estrategias para la evaluación de recursos humanos en salud. Se piensa que la elaboración y la aplicabilidad de indicadores de calidad guardan estrecha relación con la motivación y satisfacción de los profesionales, repercutiendo en la asistencia prestada a los usuarios de los servicios de salud.

Descriptores: Indicadores de calidad de la atención de salud; Garantia de la calidad de atención de salud; Recursos humanos en salud.

\footnotetext{
${ }^{1}$ Professora Titular do Departamento de Orientação Profissional da Escola de Enfermagem da Universidade de São Paulo (SP), Brasil.

${ }^{2}$ Professoras Doutoras do Departamento de Orientação Profissional da Escola de Enfermagem da Universidade de São Paulo (SP), Brasil.
} 


\section{INTRODUÇÃO}

A construção de indicadores de qualidade para a avaliação de serviços de enfermagem nas instituições hospitalares, implica na explicitação de referenciais de apoio, sob a ótica dos quais os diferentes elementos constitutivos das estruturas organizacionais, dos processos de trabalho e dos resultados da assistência prestada devem ser resgatados e analisados.

Assim, a elaboração desses indicadores requer a busca de eixos condutores que apontem para a necessidade de se considerar os seguintes aspectos: as políticas assistenciais, educacionais e gerenciais em saúde; a missão e a estrutura organizacional; os programas e as propostas de trabalho das instituições de saúde; os recursos humanos, materiais, financeiros e físicos disponíveis e as expectativas da clientela atendida.

A política de saúde no Brasil, como um dos eixos condutores das propostas assistenciais, visando à superação das dualidades clínica/epidemiológica e individual/ coletiva passou a se concretizar mediante a Reforma Sanitária e se tornar explícita e sistematizada na VIII Conferência Nacional de Saúde, em 1986, constituindo-se, em um plano político e ideológico, na gênese do Sistema Único de Saúde (SUS). Este sistema, regulado pelo Estado, teve como princípios a universalização, a eqüidade e a integralidade da atenção à saúde considerando, ainda, para a sua concretização, a regionalização, a hierarquização e a descentralização político-administrativa dos serviços ${ }^{(1)}$.

Como conseqüência dessa proposta, iniciou-se a reformulação do sistema de saúde, obrigando as instituições a recomporem suas estruturas organizacionais, bem como suas práticas e ações no setor.

Nesse contexto, se na área pública, a construção do SUS vem sendo marcada pela implementação de instrumentos legais e normativos que buscam alcançar a promoção, a efetivação e avaliação das práticas assistenciais, permitindo avanços que não se contrapõem aos interesses políticos; na esfera privada, os princípios do SUS são interpretados à luz de uma assistência vinculada às demandas de assistência à saúde, atrelada às condições socioeconômicas dos indivíduos e grupos. Portanto, interesses de ordem política, social e econômica se fazem presentes, explicando os avanços e os recuos no processo de implementação do atual sistema de saúde.

No âmbito do processo educacional, em 1996, a nova Lei de Diretrizes e Bases da Educação Nacional (LDB) assegurou, às instituições de ensino superior, autonomia didático-pedagógica. Quanto às competências dos egressos-profissionais de saúde, entre eles o enfermeiro, o Ministério de Educação e Cultura (MEC) propôs como Diretrizes para os Cursos de Graduação em Saúde, a formação de um profissional crítico e reflexivo, capaz de conhecer e intervir na problemática do processo saúde- doença, identificando as dimensões biopsicossociais de seus determinantes.

Atualmente, além da autonomia das instituições de ensino, outra característica que marca a organização curricular dos cursos superiores, é a do modelo da racionalidade técnica que privilegia o caráter instrumental da formação profissional, o que obriga as Unidades de Ensino Superior a repensarem não só a epistemologia da prática, como também os pressupostos pedagógicos onde baseiam seus currículos com vistas à formação de profissionais críticos e reflexivos.

No que se refere às políticas gerenciais, o que pode ser resgatado no processual do gerenciamento em saúde, é o fato dessas serem influenciadas e até determinadas pelos contextos político, social, econômico, educacional e de saúde vigente em cada época da sociedade.

Dessa forma, enquanto nas décadas entre 1950 a 1970 o paradigma da gerência estava pautado na construção de estruturas idealizadas e com a ênfase no produto, na década de 1980 a tônica passou a ser no cliente, surgindo a proposta de qualidade e de produtividade, estabelecendo uma nova dinâmica nos processos de trabalho e, conseqüentemente, no gerenciamento.

Nesse processo evolutivo-histórico, a partir de 1990 o gerenciamento passa a integrar, a proposta de qualidade, com destaque para as relações interpessoais, como elemento influente nos resultados institucionais. As relações de poder existentes entre os elementos integrantes e internos às instituições e os externos, no caso da saúde, os usuários, passam a ser considerados como uma variável significativa na obtenção da qualidade dos resultados do trabalho.

No atual milênio, ainda no horizonte da qualidade, a ênfase se dá segundo o paradigma do gerenciamento sensível, pelo estabelecimento de indicadores que permitam a avaliação de resultados; com a informática determinando a socialização das informações; com a necessidade de integralização dos processos de trabalho desenvolvidos pelos diferentes agentes; com a tônica na capacitação de recursos humanos; com menor quantitativo de pessoal e maior competência; com incentivo a inovação e a criatividade; com a terceirização e, conseqüente, diversificação de culturas a serem gerenciadas; com o ritmo de demandas e respostas rápidas e, finalmente com o equilíbrio entre a razão e a intuição ${ }^{(2)}$.

Em consonância com essa assertiva, a questão da dimensão humana no ambiente da qualidade deve estar no centro da discussão, uma vez que os anseios, as expectativas e a satisfação das pessoas responsáveis em concretizar esses propósitos são vitais para o alcance das metas institucionais. Para tanto, acreditam na necessidade das organizações proporcionarem condições de trabalho, estimulando a realização profissional e a satisfação pessoal de seus funcionários ${ }^{(3)}$. 
Ainda nessa perspectiva, desconhecer a importância do fator humano ou trabalhá-lo de forma inadequada tem levado ao fracasso inúmeros programas de qualidade $^{(4)}$. Portanto, é imprescindível considerar o potencial dos recursos humanos e investir na sua capacitação, uma vez que a gestão da qualidade pressupõe um estilo gerencial participativo.

Sob essa ótica, há que se considerar a necessidade de valorização das pessoas, bem como a autonomia decisória, a descentralização do poder, a socialização do saber e a reorganização do processo de trabalho.

\section{CONSTRUINDO ESTRATÉGIAS PARA AVALIAÇÃO DE RECURSOS HUMANOS EM SAÚDE}

Na saúde, decorrente das características dos processos de trabalho, a qualidade adquiriu um significado particular e diferenciado das demais atividades envolvidas na produção de bens. A prestação da assistência à saúde é realizada por grupos heterogêneos de profissionais, com formação educacional distinta.

Nesse contexto, a qualidade é definida como um conjunto de atributos que inclui um nível de excelência profissional, o uso eficiente de recursos, um mínimo de risco ao paciente-cliente, um alto grau de satisfação por parte dos usuários, considerando-se essencialmente os valores sociais existentes ${ }^{(5)}$.

Decorrente dessa proposição, a implementação de estratégias que possibilitem avaliar esses atributos vem despontando no cenário atual, sendo a construção de indicadores referida pelos profissionais de saúde, como uma necessidade na busca da eficiência e da eficácia dos resultados organizacionais. Toda instituição, cuja missão essencial é assistir o ser humano, preocupa-se com a melhoria constante do atendimento, objetivando atingir uma relação harmônica entre as áreas: administrativa, tecnológica, econômica, assistencial, de ensino e de pesquisa.

Nessa direção, a Joint Commision American Hospital Organization ${ }^{(6)}$ define indicador como uma unidade de medida de uma atividade, com a qual se está relacionado ou uma medida quantitativa que pode ser usada como um guia para monitorar e avaliar a qualidade assistencial e as atividades de um serviço.

Os indicadores são, geralmente, construídos mediante uma expressão matemática, onde o numerador representa o total de eventos predefinidos e o denominador a população de risco selecionada, observando-se a confiabilidade, a validade, a objetividade, a sensibilidade, a especificidade e o valor preditivo dos dados.

Outra característica relativa aos indicadores é que estes são considerados como um sinalizador voltado para identificar ou dirigir a atenção para assuntos específicos de resultados em uma organização de saúde, devendo periodicamente ser revisto. O emprego contínuo de indicadores trará aprimoramento e inovação na avaliação e, conseqüentemente, no planejamento, na organização e na direção das unidades de saúde ${ }^{(7,8)}$.

Cabe ressaltar, que dificilmente um indicador, de maneira estanque, é capaz de retratar a realidade; é mais provável que um grupo deles possa espelhar uma determinada situação. Logo, para garantir o acesso a um conjunto de indicadores, é fundamental a existência de um sistema de informação capaz de propiciar maiores e melhores elementos para a construção e para o uso dos mesmos $^{(9)}$.

Dessa maneira, os indicadores devem ser capazes de atender aos objetivos de melhorar a assistência ao cliente, de fortalecer a confiança da clientela, de atender às exigências de órgãos financiadores, de reduzir custos, de atrair e estimular o envolvimento dos profissionais. Nessa perspectiva, nos serviços de enfermagem, a gestão da qualidade da assistência volta-se para a prática profissional fundamentada no corpo do conhecimento da ciência enfermagem, nas habilidades, nas crenças e nos valores individuais, profissionais e institucionais.

Há ainda que se considerar, a importância de se elaborar indicadores passíveis de serem estudados e comparáveis, no âmbito do gerenciamento do Serviço de Enfermagem, com os padrões internos e externos à instituição.

O processo de validar indicadores conduz o enfermeiro a encontrar respostas para questões gerenciais, assistenciais, econômicas e legais, mostrando os resultados do atendimento prestado e possibilitando a implementação de ações de melhoria, baseadas em padrões de qualidade ${ }^{(10)}$.

A construção de indicadores para a avaliação da gestão de recursos humanos permite detectar a eficiência e a eficácia das ações gerenciais e a partir de avaliação desses indicadores, aprimorar os processos de trabalho.

\section{CONSIDERAÇÕES FINAIS}

Em uma visão prospectiva, visualiza-se como imprescindível considerar as políticas governamentais de saúde e de educação no gerenciamento da assistência à saúde, respeitando, ainda, a missão e a estrutura organizacional; os programas e as propostas de trabalho das instituições de saúde; os recursos humanos, materiais, financeiros e físicos disponíveis, bem como as expectativas dos usuários dos serviços de saúde.

Salienta-se que, no processo de investigação cabe aos pesquisadores buscar instrumentos que subsidiem a superação de obstáculos, tanto no âmbito educacional quanto no gerencial, visando a elaboração de indicadores que reflitam uma dada realidade. 
No caminho que leva à qualidade, envolver os recursos humanos da instituição é essencial, bem como proporcionar estratégias que conduzam as pessoas a trabalhar com entusiasmo, criatividade e motivação. A ausência da participação, da capacitação e do envolvimento dos profissionais da instituição não permite a consolidação de processos de qualidade, uma vez que estes dependem de esforços e desempenho individual e coletivo.

Há que se pensar na implementação de uma política de qualificação de pessoal para enfrentar os desafios do $3^{\circ}$ milênio e vontade política para transformar os serviços de saúde, os quais, certamente, constituir-se-ão nos pilares básicos para a melhoria da qualidade dos serviços prestados à população brasileira ${ }^{(11)}$.

Assim, torna-se imperativo, a elaboração de indicadores de recursos humanos como uma prática sistemática nas organizações de saúde, de modo a garantir o desenvolvimento das habilidades e potencialidades de seus profissionais.

\section{REFERÊNCIAS}

1. $8^{a}$ Conferência Nacional de Saúde; 1986; Brasília, DF. Brasília: Centro de Documentação do Ministério da Saúde; 1987. p. 361-89.

2. Kurcgant P. A práxis do gestor em enfermagem. In: Conferência do $1^{\circ}$ Simpósio Norte-Nordeste de Administração em Enfermagem; 2004 set 2-3; João
Pessoa, PA. João Pessoa: Universidade Federal da Paraíba; 2004.

3. Leitão RER, Kurcgant P. Qualidade na prática gerencial da enfermagem. Niterói: Intertexto; 2004.

4. Silva VEF. A avaliação da qualidade do processo. Rev Paul Enferm. 1997;16(1-3):67-71.

5. Organização Mundial da Saúde (OMS). Avaliação dos programas de saúde: normas fundamentais para sua aplicação no processo de gestação para o desenvolvimento nacional na saúde. Genebra; 1981.

6. Joint Commission on Accreditation of Healthcare Organizations (JCAHO). Joint Commission International Accreditation Standards for Hospitals. 2th ed. [text on the Internet]. Illinois; 2004. [cited 2004 Dez 6]. Available from: http://www.jcrinc.com/ publications.asp

7. Bittar OJN. Indicadores de qualidade e quantidade em saúde. Rev Adm Saúde 2001; 3(12): 21-8.

8. Bittar OJN. Indicadores de qualidade e quantidade em saúde. Rev Adm Saúde 2004; 6(22): 15-8.

9. Malik AM, Schiesari LMC. Qualidade na gestão local de serviços e ações de saúde. São Paulo: Faculdade de Saúde Pública da USP; 1998.

10. Denser CPAC. Indicadores: instrumento para a prática de enfermagem com qualidade. In: Bork AMT, organizador. Enfermagem de excelência: da visão à ação. Rio de Janeiro: Guanabara Koogan; 2003. p. 89-100.

11. Adami NP. A melhoria da qualidade nos serviços de enfermagem. Acta Paul Enferm. 2000; 13(1 ed esp):190-6. 